\title{
Twentieth-Century Trends in Runoff, Evapotranspiration, and Soil Moisture in the Western United States*
}

\author{
Alan F. Hamlet \\ CSES Climate Impacts Group, and Department of Civil and Environmental Engineering, University of Washington, \\ Seattle, Washington \\ Philip W. Mote \\ CSES Climate Impacts Group, University of Washington, Seattle, Washington \\ MARTYN P. CLARK \\ National Institute for Water and Atmospheric Research, Christchurch, New Zealand \\ DenNis P. LeTtenMAIER \\ Department of Civil and Environmental Engineering, and CSES Climate Impacts Group, University of Washington, \\ Seattle, Washington
}

(Manuscript received 12 July 2005, in final form 2 August 2006)

\begin{abstract}
A physically based hydrology model is used to produce time series for the period 1916-2003 of evapotranspiration (ET), runoff, and soil moisture (SM) over the western United States from which long-term trends are evaluated. The results show that trends in ET in spring and summer are determined primarily by trends in precipitation and snowmelt that determine water availability. From April to June, ET trends are mostly positive due primarily to earlier snowmelt and earlier emergence of snow-free ground, and secondarily to increasing trends in spring precipitation. From July to September trends in ET are more strongly influenced by precipitation trends, with the exception of areas (most notably California) that receive little summer precipitation and have experienced large changes in snowmelt timing. Trends in the seasonal timing of ET are modest, but during the period 1947-2003 when temperature trends are large, they reflect a shift of ET from midsummer to early summer and late spring. As in other studies, it is found that runoff is occurring earlier in spring, a trend that is related primarily to increasing temperature, and is most apparent during 1947-2003. Trends in the annual runoff ratio, a variable critical to western water management, are determined primarily by trends in cool season precipitation, rather than changes in the timing of runoff or ET. It was found that the signature of temperature-related trends in runoff and SM is strongly keyed to mean midwinter [December-February (DJF)] temperatures. Areas with warmer winter temperatures show increasing trends in the runoff fraction as early as February, and colder areas as late as June. Trends toward earlier spring SM recharge are apparent and increasing trends in SM on 1 April are evident over much of the region. The 1 July SM trends are less affected by snowmelt changes and are controlled more by precipitation trends.
\end{abstract}

* National Oceanic and Atmospheric Administration Contribution Number 1146.

Corresponding author address: Dr. Alan Hamlet, CSES Climate Impacts Group, University of Washington, Box 352700, Seattle, WA 98195.

E-mail: hamleaf@u.washington.edu

DOI: $10.1175 / J C L I 4051.1$

(C) 2007 American Meteorological Society 


\section{Introduction and background}

Strong topographic controls on precipitation $(P)$ and temperature $(T)$ are present in the western United States (e.g., Daly et al. 1994). Much of the $P$ occurs in the mountainous parts of the region in the cool season from October to March, particularly at higher elevations, although some areas in the Southwest receive considerable precipitation in the warm season from April to September. The coastal mountains in Washington, Oregon, and California are relatively warm in winter in comparison with the Rocky Mountains, and also have much greater cool season precipitation (see Fig 1, Hamlet et al. 2005). Different temperature regimes largely determine how much of the cool season $P$ is stored as snow, and also play a strong role in determining the $T$ sensitivity of snow accumulation and melt processes in different areas (Hamlet et al. 2005; Knowles and Cayan 2004; Mote et al. 2005; Mote 2006). Snowpack plays a central role in runoff production in the western United States (Serreze et al. 1999). In many mountain watersheds the water stored as snow in spring accounts for a dominant fraction of the warm season (April-September) runoff contributing to streamflow.

Over the past several decades a number of hydrologic modeling studies at the river basin scale have demonstrated that estimated increases in cool season temperatures associated with rising global greenhouse gas concentrations would alter the hydrologic cycle in mountain watersheds in the western United States (e.g., Gleick 2000; Hamlet and Lettenmaier 1999; Knowles and Cayan 2002; Lettenmaier et al. 1999; Miller et al. 2003; Mote et al. 2003; Stewart et al. 2004). Systematically warmer temperatures in snowmelt-dominant and transient-snow watersheds result in reduced (and earlier) peak snowpack, more runoff in cool season, earlier spring peak flows, reduced warm season water availability and late summer low flows, increased evapotranspiration (ET) in the warm season, and (in some studies) an altered seasonal cycle of soil moisture (SM) recharge and depletion (e.g., Hamlet and Lettenmaier 1999). These kinds of hydrologic changes have also been shown to have important water resources implications in a number of case studies (Christensen et al. 2004; Hamlet and Lettenmaier 1999; Knowles and Cayan 2004; Payne et al. 2004; Service 2004; Van Rheenen et al. 2004).

In previous work we have examined in detail twentieth-century trends in simulated spring snowpack over the western United States and have compared them to observed trends from snow course data (Hamlet et al. 2005; Mote et al. 2005) Mote (2006) corroborated the findings of the earlier modeling studies using alterna- tive statistical approaches. Some important conclusions from these studies include the following.

- Simulations from physically based hydrologic models (Hamlet et al. 2005; Mote et al. 2005) and regression models (Mote 2006) reproduce the spatiotemporal variations in observed spring snowpack to a remarkable degree, demonstrating that observed trends in $T$ and $P$ coupled with topographic variations in cool season climate are adequate to explain most of the observed trends in spring snowpack over the western United States.

- Without observed trends in $P$, essentially the entire western United States would have experienced losses of 1 April snowpack during the twentieth century due to widespread warming.

- The observed trends in snow water equivalent (SWE) depend strongly on winter temperature regimes. The areas where the greatest SWE changes have occurred are in near-coastal parts of the western United States where winter temperatures are typically close to freezing in midwinter.

- The date of peak snow accumulation and 90\% melt have been moving earlier in the year (up to 45 days earlier in sensitive areas) from 1916 to 2003, despite modest increases in $P$ over this same time period. These changes are mostly due to $T$ trends.

- While there is clear evidence in snowpack records of widespread warming across the western United States in the twentieth century, there is little evidence of any consistent long-term trends in snowpack across the western United States associated with trends in $P$. This supports the hypothesis that $\mathrm{P}$, at least so far, has been predominantly controlled by decadal-scale climate variability rather than effects associated with global climate change.

Given the importance of snow dynamics to the hydrologic cycle in western watersheds, the observed changes in snowpack strongly suggest that we should also expect associated changes in runoff, ET, and SM dynamics in observed records and hydrologic simulations. Several recent studies have shown that temperature-related shifts in runoff timing are indeed evident in observed unregulated streamflow records (Regonda et al. 2005; Stewart et al. 2005).

Observational studies are crucial to the assessment of observed climate change, however modeling studies are also needed to extend records back to the early part of the century (when relatively few observations are available) and to provide spatial and temporal resolution and continuity that are missing from the observed records. Furthermore, model simulations can explicitly show the role of $T$ and $P$ trends in the observed 


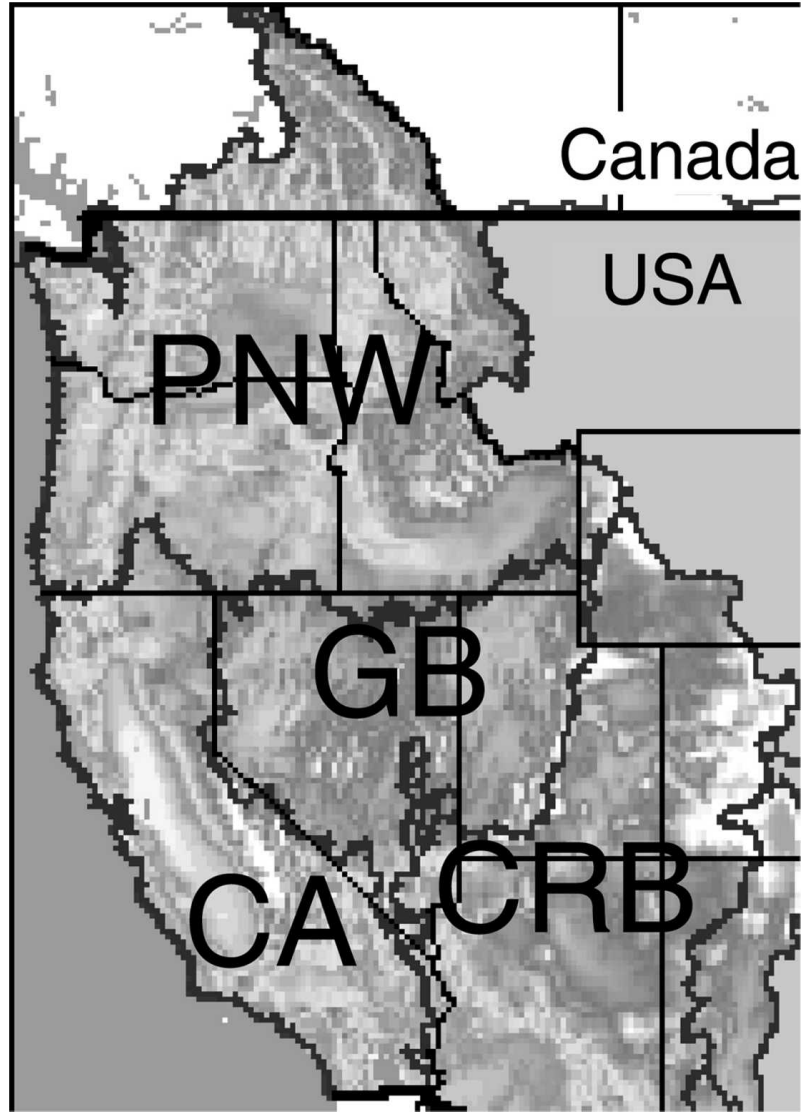

FIG. 1. Map of the simulation domain and subregions discussed in the results.

changes, and can be used to analyze components of the hydrologic cycle that are typically unmeasured (particularly ET and SM).

In this study (following methods first developed in the companion study by Hamlet et al. 2005) we use the Variable Infiltration Capacity (VIC) model of Liang et al. (1994) to produce long time series of key hydrologic variables over the western United States as described in the following section. For convenience in describing the results we partition the domain into four regions: the Columbia River basin and coastal drainages of the $\mathrm{Pa}-$ cific Northwest (PNW); California (CA-mostly the Sacramento and San Joaquin River basins), the Great Basin (GB-which consists of numerous rivers that flow to the closed interior of the GB), and the Colorado River basin (CRB) (Fig. 1).

Following the general approach used by Hamlet et al. (2005) for evaluating trends in snowpack, we quantify trends in model simulations of ET, runoff, and SM associated with observed trends in $T$ and $P$ for each model grid cell over two retrospective periods: 1) 19162003 (the entire period of record available) and 2)
1947-2003 [a period encompassing one full cycle of the Pacific decadal oscillation (PDO) and the well-documented shift from cool to warm phase PDO in 1976-77 (Mantua et al. 1997)].

\section{Hydrologic simulation model and driving data}

In this study (as in Hamlet et al. 2005) we use the VIC hydrologic model (Liang et al. 1994; Cherkauer and Lettenmaier 2003) implemented over the western United States at $1 / 8^{\circ}$ spatial resolution (Fig. 1). A temporally adjusted, gridded daily time step $P$ and $T$ dataset from 1915 to 2003 was used to drive the VIC model. By construction, these adjusted datasets reproduce, at monthly time scales, the trends in $T$ and $P$ from the Historical Climatology Network (HCN; Karl et al. 1990) and the Historical Canadian Climate Database (HCCD; Mekis and Hogg 1999; Vincent and Gullett 1999). The methods used to produce the driving data, and evaluation of the resulting hydrologic simulations using observed streamflow records, are reported in more detail by Hamlet and Lettenmaier (2005).

Daily time step VIC water balance simulations were carried out using a 1-h snow model time step. The first 9 months of the simulations (1 January 1915-30 September 1915) were used for model spinup and have been excluded from the subsequent analysis resulting in a time series of 88 water years (October-September) from 1916 to 2003. Model spinup requirements are somewhat different for SM than for ET and runoff. In relatively wet areas (such as the mountainous areas that accumulate substantial snowpack in cool season that we primarily analyze here) a few years of model spinup has been shown to be adequate for SM studies (e.g., Cosgrove et al. 2003). To help ensure that the initial SM conditions do not unduly influence the long-term trends in the driest parts of the domain, however, we examine SM trends from 1920 onward, allowing for a 5-yr model spinup. Additional details on the hydrologic model and its implementation are reported by Hamlet et al. (2005).

\section{Evaluation of the hydrologic model}

In the following sections we evaluate the performance of the hydrologic model in simulating various elements of the monthly water balance.

\section{a. Snowpack}

Simulated trends in 1 April SWE produced using the VIC model over the western United States have been previously evaluated in detail by Mote et al. (2005) and Hamlet et al. (2005). Good overall agreement was also found between the results produced by the physically 

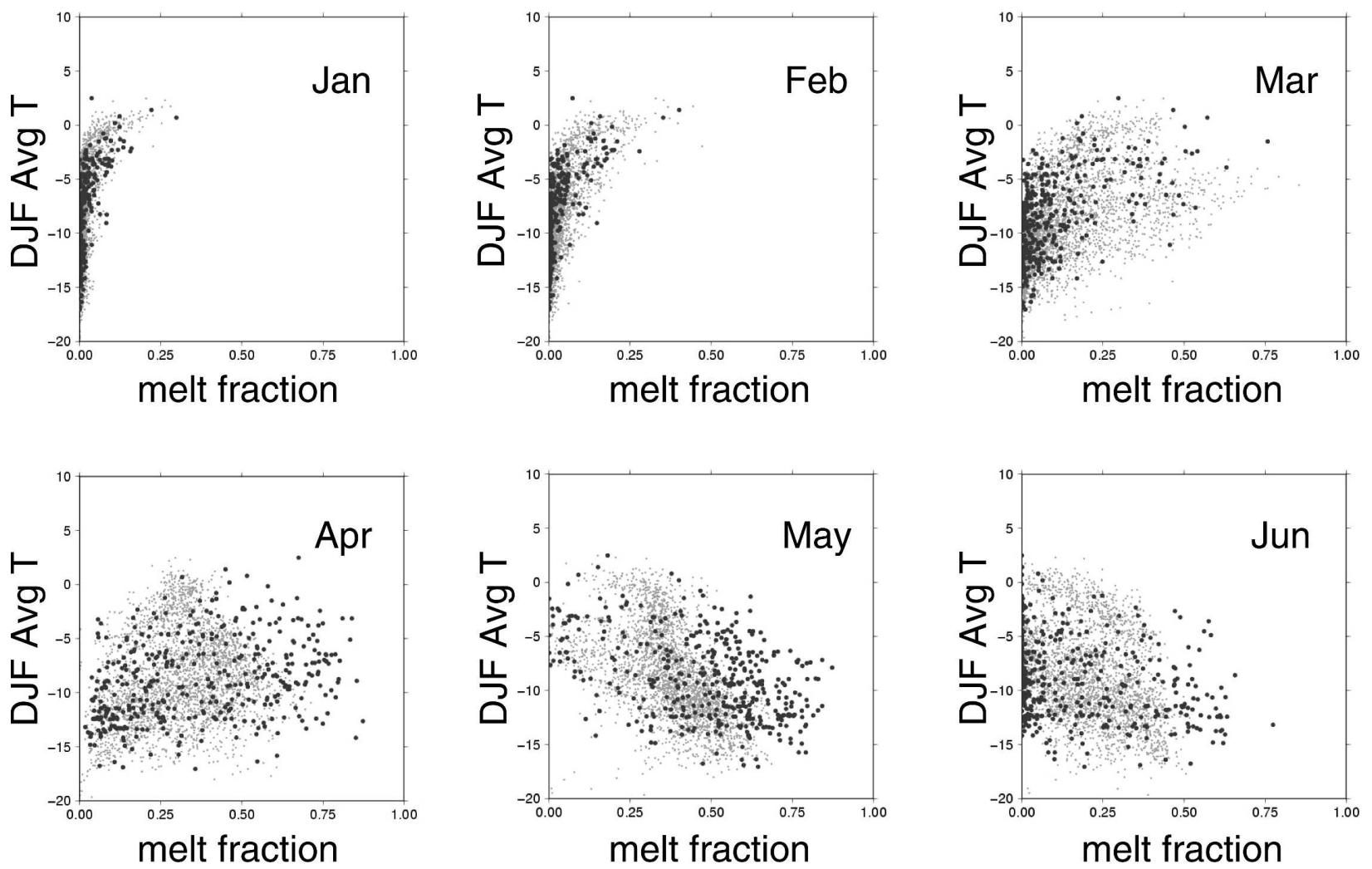

FIG. 2. Simulated and observed total monthly snowmelt (including transient melt) normalized by the long-term mean of the peak snowpack during 1984-2003 at each location. Small gray dots are VIC cells, large black dots are SNOTEL stations. Only sites with more than $200 \mathrm{~mm}$ of SWE on 1 April are included in the plots to remove low elevation sites from the VIC analysis.

based model (Hamlet et al. 2005) and those produced by alternative statistical approaches (Mote 2006). Over most of the domain the model closely reproduces the macroscale trends in the observations as a function of December-February (DJF) temperatures. Some bias in the model's SWE trends was observed in the Sierra Nevada Mountains in CA, however, where the VIC simulations tended to overestimate the magnitude of observed negative trends in snowpack. These discrepancies could be related to a spring temperature bias in the VIC meteorological driving data (see Hamlet et al. 2005 for more details), but could also be related to sampling bias in the observations, misrepresentation of seasonal precipitation trends or temperature inversions at high elevations, or other more complicated meteorological features not captured in the driving datasets. Results for CA shown in this study should be interpreted with some caution because of the model bias in this part of the domain.

\section{b. Snowmelt}

Daily time step point observations from the National Resources Conservation Service (NRCS) Snowpack
Telemetry (SNOTEL) observing network provide useful information on the timing of snowmelt that can be used to evaluate the spatial-temporal patterns of snowmelt produced by the VIC model. Due to differences in scale (point versus grid cell area average), aspect, vegetation coverage (SNOTEL sites are usually located in open areas, whereas the model simulates canopy effects averaged over a large area), and potential effects due to the thermal inertia of snow pillows used at SNOTEL stations, we do not expect excellent finescale agreement between the model simulations and the point observations. However, Fig. 2 shows that the relationship between midwinter temperatures and the seasonal cycle of snowmelt are captured by the model. Overall the model produces more melt in March and less in May than is apparent in the observations; however it is not immediately clear if the model or the observations is more representative of average conditions over the domain. (Note that the sum of the fractions shown in Fig. 2, when summed across all months are frequently larger than 1.0 during the snowmelt season, particularly in areas where there is substantial transient snow.) 

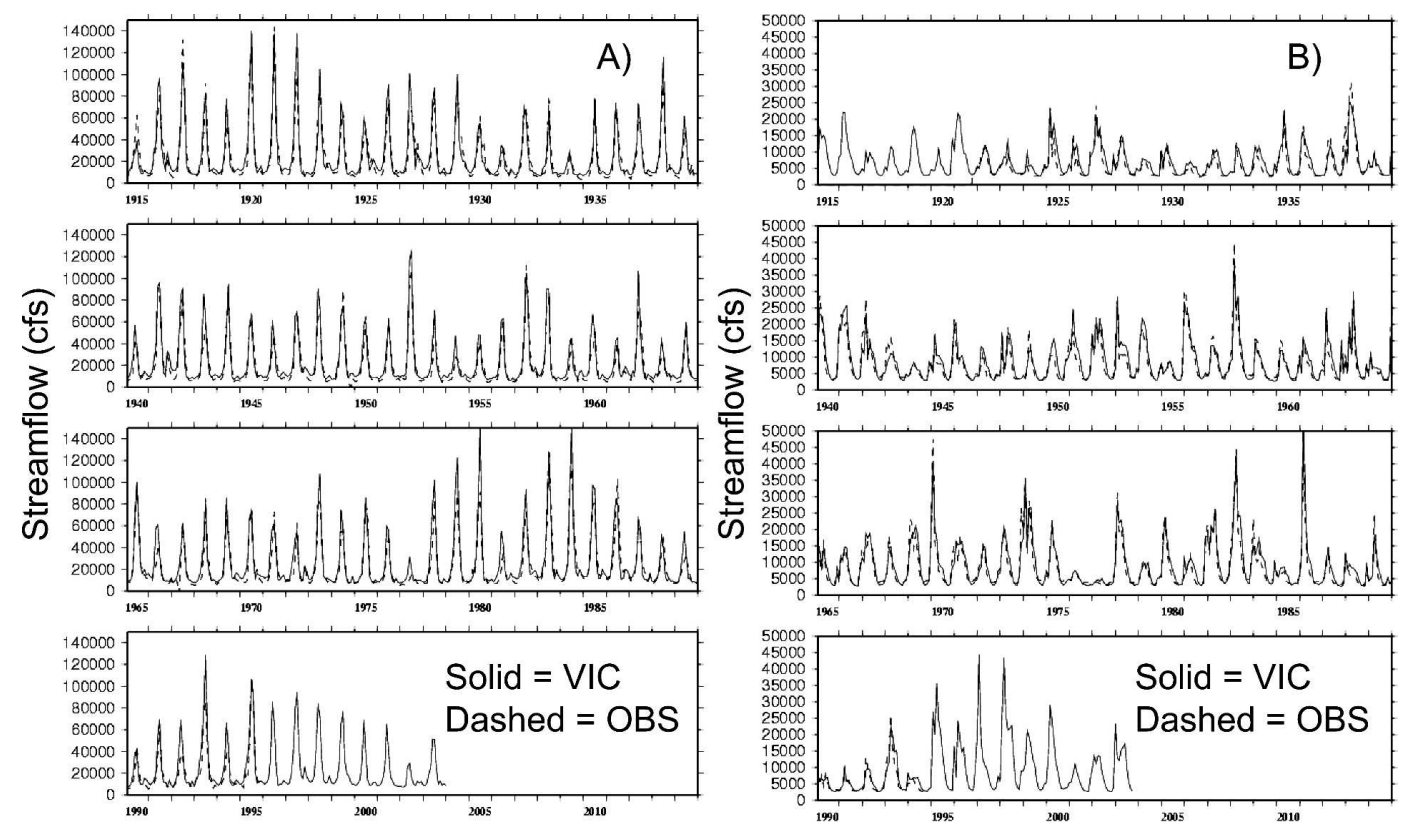

FIG. 3. Comparison of naturalized streamflow observations and simulated natural streamflows for the (a) Colorado River at Lee's Ferry, AZ (inflows to Hoover Dam) and (b) the Sacramento River at Shasta Dam near Redding, CA (inflows to Shasta Dam).

\section{c. Streamflow}

The VIC model, in general, produces high-quality monthly streamflow simulations (note that throughout this paper, we refer to simulated naturalized flows, i.e., the streamflows that would occur in the absence of water management, such as regulation by upstream dams, and/or streamflow diversions) in moderate to large river basins across the western United States (Maurer et al. 2002). As an example of the model's performance in reproducing observed (naturalized) streamflow, we show a time series for the Colorado River at Lee's Ferry, Arizona, and the Sacramento River at Shasta Dam, CA (Fig. 3). The VIC model was calibrated (by adjusting model parameters associated with infiltration and soil water transport (see Maurer et al. 2002) using driving data only from the post-1950 period. The consistent validation of the model simulations in the pre1950 period attests both to the temporal consistency of the driving data used in this study and the ability of the model to successfully capture the hydrologic variability associated with different climatic regimes from first principals using $P$ and $T$ data as the primary drivers. Although systematic model bias and random errors tend to be larger at smaller spatial scales, Hamlet and Lettenmaier (2005) demonstrate that trends in the errors are relatively small, again attesting to the temporal consistency of the driving datasets and their appropriateness for the kind of trend analyses we undertake in this study.
The model was also found to be well suited to the task of identifying long-term trends in the seasonality of streamflow at the river basin scale. Trends in the simulated fraction of annual streamflow occurring from May to September and June to September (not shown) were evaluated for several river sites in the PNW where suitable naturalized flow observations were available. The model's performance in estimating the long-term trends in seasonal streamflow timing was, in general, quite good, random errors in the year-to-year values not withstanding.

\section{d. Soil moisture and evapotranspiration}

The VIC model uses a fairly complex and explicit conceptual framework to account for variations in ET and SM. The ET in the model is based on the PenmanMonteith approach (Shuttleworth 2003) and explicitly accounts for interception of precipitation and the attenuation of wind and solar radiation associated with the vegetation canopy (Liang et al. 1994). Model parameterization of vegetation characteristics includes estimates of stomatal resistance and seasonal variations in leaf area index and an explicit representation of root distribution in the soil column, which determines how the model extracts moisture from the three soil layers during simulation of transpiration. The soil column in VIC (as implemented here) is divided into three layers. The thin upper layer $(\sim 10 \mathrm{~cm})$ simulates "fast" runoff processes in near-surface soil layers, and thicker inter- 
mediate $(\sim 50 \mathrm{~cm})$ and lower layers $(\sim 1.0-1.5 \mathrm{~m})$ represent "slower" storage and drainage processes contributing to base flow.

The VIC model's simulation of the seasonal cycle of SM has been evaluated in detail for a limited number of observing sites at which suitable records are available in the United States and Eurasia (Maurer et al. 2002; Nijssen et al. 2001). In these comparisons, the model reproduced the seasonal dynamics of SM storage with reasonable fidelity. There are few direct observations of ET and SM storage in the western United States with which to explicitly evaluate the model simulations over the different climatic regimes and soil characteristics considered in this study; however, Maurer et al. (2002) found good agreement between the model and observed soil moisture over Illinois, and Robock et al. (2003) found good overall agreement between the spatial variability of SM simulated by VIC and a network of SM observations from the Oklahoma Mesonet. Based on the model's realistic and physically based representation of hydroclimatic mechanisms, and given that the model reproduces the seasonal timing of water inputs from snowmelt (Fig. 2), the monthly timing of runoff, and the annual runoff ratio reasonably well, we argue that the model simulations of SM and ET are a useful and self-consistent surrogate for observations as well.

Simulated ET in the model is sensitive to the difference between the daily temperature maxima and minima $\left(T_{\max }\right.$ and $\left.T_{\min }\right)$ in the meteorological driving data, which ultimately determines the shortwave radiation attenuation due to inferred "cloudiness" in the model using methods developed by Thornton and Running (1999). These methods parameterize the relationship between the attenuation of solar radiation and the difference between $T_{\max }$ and $T_{\min }$. It is not entirely clear if the empirically derived parameters remain stationary with changing climate, however the model does simulate changes in ET associated with a changing difference between $T_{\max }$ and $T_{\min }$ that are consistent with changes in atmospheric moisture content and/or the attenuation of incoming solar radiation by clouds. The Penman-Monteith equation is also sensitive to increasing daily average temperatures (which determine the saturation vapor pressure) and to $T_{\min }$, which partially determines the dewpoint in the model simulations and therefore the vapor pressure deficit used in the Penman-Monteith equation. The temperature-related effects on ET in the model simulations can therefore be broadly interpreted as the trends in ET due to changing energy availability and saturation vapor pressure associated with trends in inferred cloudiness and absolute temperature, respectively. Simulated ET is also sensi- tive to wind speed, although any systematic effects due to wind variations are secondary to those associated with precipitation and temperature trends in the simulations, particularly since a daily wind climatology is used in the early part of the simulation period (1915-48; Hamlet and Lettenmaier 2005).

\section{Approach}

For each $1 / 8^{\circ}$ grid cell, the VIC model produces a daily time series of water balance variables. For runoff and ET, these daily values were aggregated to monthly averages. For SM, the value on the first day of the month was used, rather than the monthly average value. Runoff is also reported as a fraction of annual flow occurring in each month as a measure of runoff timing. Linear trends in simulated monthly ET, runoff (the sum of surface runoff and base flow contributing to streamflow in the model), and SM were then calculated for each grid cell. Note that trends in these quantities are not integrated spatially, and linear trends for each variable are calculated independently for each grid cell. As in Hamlet et al. (2005), three separate model simulations were carried out to help understand the relative effects of trends in $P$ and $T$ on the results.

1) Base run (BR): Unperturbed $P$ and $T$ data from the gridded meteorological data (daily total $P, T_{\max }$ and $T_{\min }$, and wind speed) were used to drive the model. Trends in hydrologic variables are the result of both $T$ and $P$ variations.

2) Fixed $P$ run (FPR): The $P$ forcing data were fixed (at monthly time scales) at the climatological value for each grid cell, but daily $T$ was allowed to vary as in the original time series (as in 1 above). Trends in hydrologic variables are predominantly determined by $T$ trends alone.

3) Fixed $T$ run (FTR): $T_{\max }$ and $T_{\min }$ were fixed (at monthly time scales) at the climatological value for each grid cell, but daily precipitation varied as in the original time series (as in 1 above). Trends in hydrologic variables are predominantly determined by $P$ trends alone.

For the FPR and FTR, the forcing data were perturbed as follows: for each grid cell, a monthly climatological value for $P, T_{\max }$ and $T_{\min }$ was calculated for each calendar month. Then the daily time series of the variable to be held constant was forced to reproduce this climatological value in each month of the simulation [i.e., the daily values within the month are rescaled for each month in the time series so that the monthly totals $(P)$ or averages $\left(T_{\max }\right.$ and $\left.T_{\min }\right)$ are equal to the climatological value]. This method preserves the daily 
covariance between $T$, $P$, solar radiation, and other forcing variables, while removing the trends and monthly variation in the fixed variable from the simulation. If $P, T_{\max }$, and $T_{\min }$ were all held fixed in this manner, the monthly mean of the resulting simulated hydrologic variables would be comparable (although not equal) to the long-term mean for each calendar date in the base simulation and any trends in the simulated hydrologic variables would be small and related to secondary effects such as daily variability within the month.

In the FTR, trends in inferred cloudiness, although not completely eliminated, are strongly reduced. The number of cloud-free days in each month remains the same as in the unperturbed driving data; however, the sum of ( $T_{\max }$ and $\left.T_{\min }\right)$ over all the days in each month (which is related to the estimated total shortwave radiation input in each month in the model) has no trend. Similar time-scale issues are present with regard to daily precipitation values in the FPR. The timing of precipitation and the number of days with rain within each month remains as in the original time series, but the monthly precipitation totals have no trend.

Several different metrics are used to evaluate systematic changes in timing and absolute value of water balance terms. Fifty-year cumulative trends (i.e., the annual trend times an arbitrary time period of $50 \mathrm{yr}$ ) in the date of occurrence of $50 \%$ of total cumulative water year runoff and ET, and the date of occurrence of $80 \%$ of maximum water year SM are used to assess systematic changes in seasonal timing of these variables. The date of $80 \%$ of maximum water year SM was used since $\mathrm{SM}$ is already an integrated variable and cumulative metrics are less appropriate. For runoff, trends in the fraction of total water year runoff occurring in a particular month were also employed as a timing sensitive metric, in part because similar metrics have been used in observational studies by Regonda et al. (2005) and Stewart et al. (2005). For variables that vary considerably in absolute value over the domain (e.g., $P$, ET, runoff, and SM), relative trends (i.e., annual trends normalized by the long-term mean) are reported.

\section{Results and discussion}

\section{a. Trends in precipitation and temperature}

Figure 4 shows a temporally smoothed time series of cool and warm season meteorological variables averaged over the four large river basins in the study domain (see figure caption for details). Table 1 show linear trends in $P, T_{\text {max }}$, and $T_{\text {min }}$ extracted from the model driving data for the cool season (OctoberMarch) and warm season (April-September) for the period of record for 1916-2003 and 1947-2003. The period 1916-2003 is characterized by modest upward trends in precipitation and temperature. As noted above these trends are, by construction, in close agreement with those present in the HCN and the HCCD. Temperature trends are larger in cool season than in warm season during 1916-2003 but trends in the two seasons are more comparable during 1947-2003. Trends in maximum temperature $\left(T_{\max }\right)$ are smaller than for minimum temperature $\left(T_{\min }\right)$ overall, and temperature trends for the latter period, 1947-2003, are both larger than for the longer record, 1916-2003, and show a greater difference in the rate of warming between $T_{\max }$ and $T_{\min }$. These trends are comparable to those shown in studies of station data (e.g., Mote et al. 2005; Knowles et al. 2006), and the different rates of increase between $T_{\max }$ and $T_{\min }$ are consistent in their overall character with the analyses included in the Intergovernmental Panel on Climate Change (IPCC) 2001 report (Houghton et al. 2001).

As noted in the introduction, cool season $P$ trends, although shown to be generally positive across the western United States during 1916-2003, are very different in the 1947-2003 period in the PNW, and seem to be more strongly controlled by decadal variability associated with the PDO in each region than by systematic changes associated with regional warming. Trends in warm season $P$, however, are generally upward and are more consistent for different time periods (except in the CRB).

The gridded driving data contain relatively little $o b$ served information about differences in trends with elevation, because the majority of stations used to construct the gridded meteorological driving dataset are at moderate or low elevations. Thus, the time history of the gridded data (and therefore the temporal trend) is mostly controlled by low- and moderate-elevation station data. However, Mote et al. (2005) demonstrate, using snow course observations, that (except possibly in CA) an elevational bias in the simulated VIC snow trends is not apparent, which suggests that if there are differences in high- and low-elevation trends in temperature and precipitation, they are relatively small in comparison with the overall trends, or affect only very high elevations where there are few observations.

\section{b. Long-term water balance simulations}

To help illustrate some of the hydrologic characteristics of each basin that influence the results of this study, we show a simulated long-term average water balance (1916-2003) for the four large river basins that compose our study domain (Fig. 5). The importance of snowpack in the hydrologic cycle discussed in the in- 

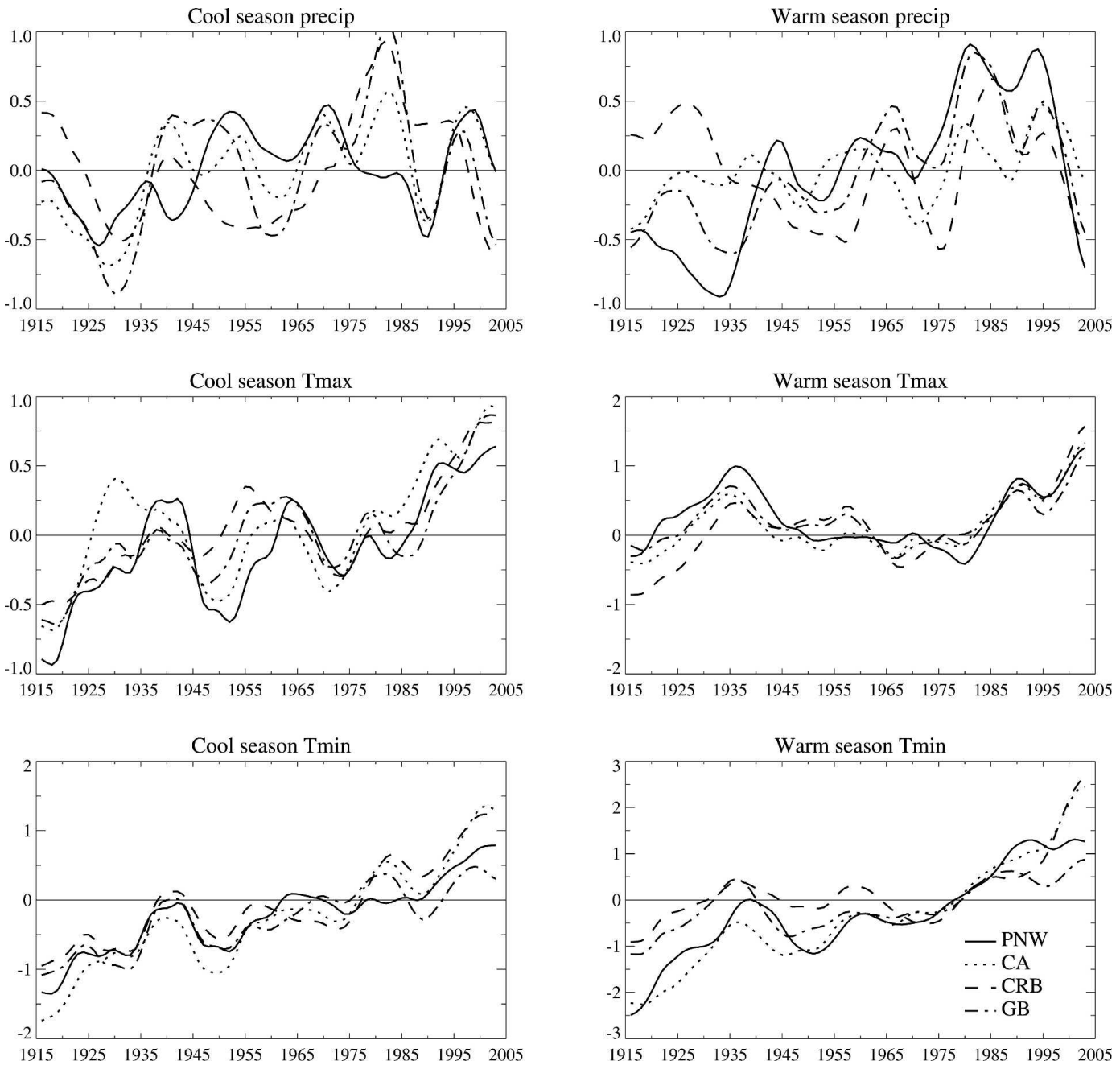

FIG. 4. Temporally smoothed, regional average cool and warm season meteorological time series for four large-scale basins. Plotted data are standardized anomalies (relative to 1961-90) during 1916-2003 smoothed to emphasize periods $>10 \mathrm{yr}$ using a locally weighted regression scheme (Cleveland 1993) after reflecting the time series around both endpoints.

TABLE 1. Regional-scale meteorological trends during 1916-2003 and 1947-2003 for cool season (October-March) and warm season (April-September): $P\left(\%\right.$ century $\left.^{-1}\right)$ and $T\left({ }^{\circ} \mathrm{C}\right.$ century $\left.{ }^{-1}\right)$.

\begin{tabular}{|c|c|c|c|c|c|c|}
\hline & & & PNW & $\mathrm{CA}$ & $\mathrm{CRB}$ & GB \\
\hline \multirow[t]{4}{*}{ Precipitation } & Cool season & 1916-2003 & 7.86 & 18.28 & 8.90 & 10.61 \\
\hline & & 1947-2003 & -11.07 & 9.88 & 24.07 & -0.91 \\
\hline & Warm season & $1916-2003$ & 27.67 & 12.69 & -2.38 & 24.08 \\
\hline & & $1947-2003$ & 16.16 & 15.91 & 16.74 & 20.78 \\
\hline \multirow{4}{*}{$T_{\max }$} & Cool season & $1916-2003$ & 1.01 & 0.88 & 1.07 & 1.11 \\
\hline & & 1947-2003 & 1.93 & 2.09 & 1.33 & 1.52 \\
\hline & Warm season & $1916-2003$ & 0.22 & 0.67 & 1.02 & 0.39 \\
\hline & & $1947-2003$ & 1.49 & 1.75 & 1.29 & 1.19 \\
\hline \multirow[t]{4}{*}{$T_{\min }$} & Cool season & $1916-2003$ & 1.67 & 1.81 & 1.44 & 1.30 \\
\hline & & $1947-2003$ & 2.27 & 2.67 & 2.36 & 1.65 \\
\hline & Warm season & 1916-2003 & 1.35 & 1.90 & 0.96 & 0.78 \\
\hline & & $1947-2003$ & 1.93 & 2.54 & 1.84 & 1.37 \\
\hline
\end{tabular}



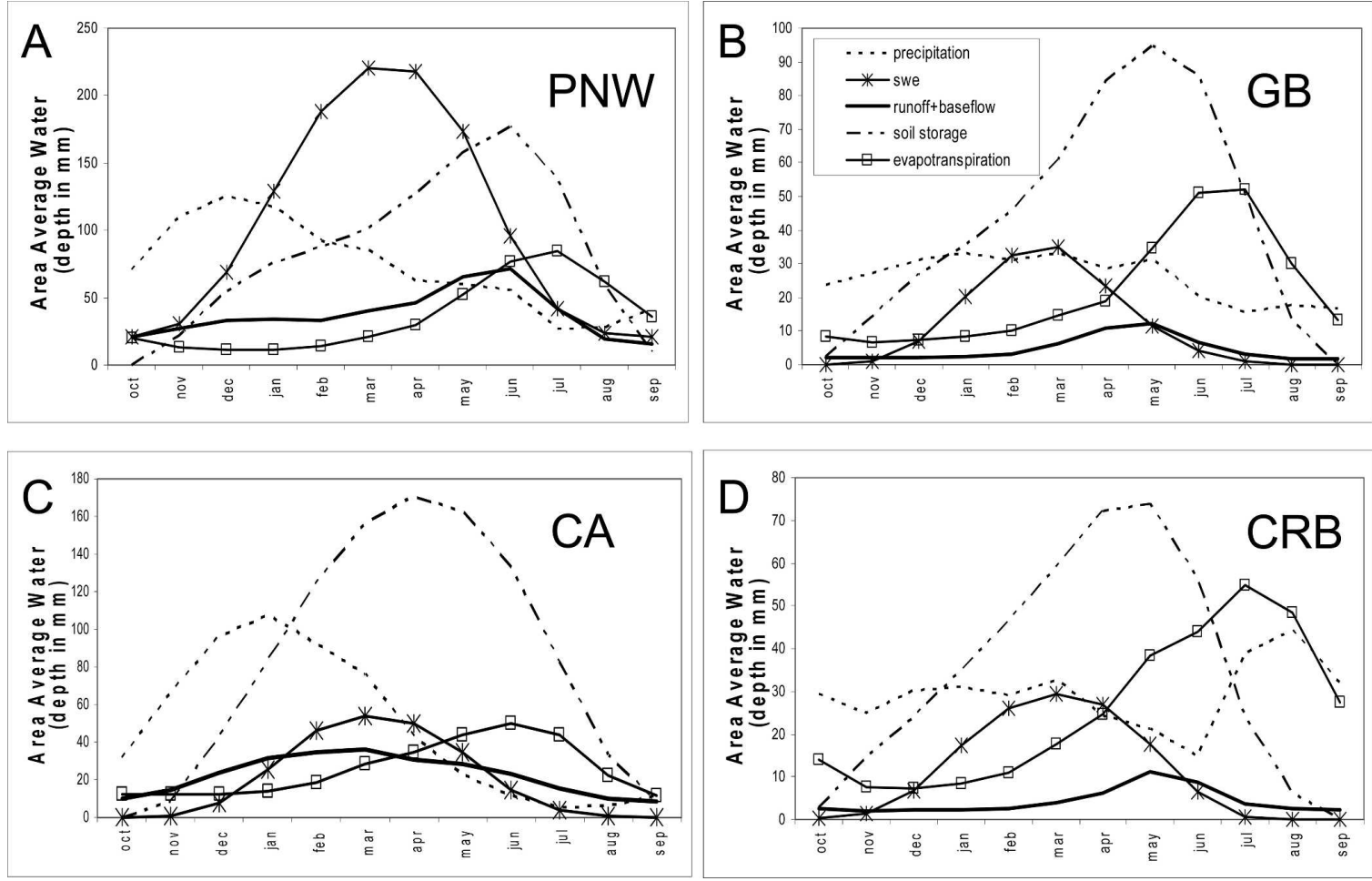

FIG. 5. Long-term average water balance for four large river basins: (a) PNW, (b) GB, (c) CA, and (d) CRB. Average residual soil moisture is subtracted from the soil moisture data before plotting.

troduction is readily apparent in these figures. Despite the fact that the simulated SM reservoir is a larger storage term than snowpack in the water balance for much of the western United States, it is only through the relatively rapid and sustained input of snowmelt that these hydrologic systems generate significant runoff in summer.

With some exceptions in the northern part of the PNW, ET in the western United States is larger than precipitation from April to September, and summer precipitation is mostly lost to ET and does not typically contribute greatly to streamflow at the spatial scales considered here. The warm season contribution to streamflow is therefore approximately equal to the (negative) change in the soil and snow storage terms less the evaporation in excess of warm season $P$. Seasonal recharge of the soil column is a complex function of the seasonality of precipitation, inputs of snowmelt in spring, and losses from ET or drainage; however, basin average soil moisture in the simulations typically peaks in May or June toward the end of the snowmelt season.

\section{c. Overall trends in the timing of ET, runoff, and SM}

To begin with, we show overall trends in the timing of ET, runoff, and SM recharge. Figures 6 and 7 show 50-yr cumulative trends (annual trend times 50) in the date of occurrence of $50 \%$ of the total water year ET and runoff, and in the date of occurrence of $80 \%$ of the maximum SM. Downward trends in these values indicate more ET, runoff, or SM recharge occurring earlier in the water year.

The changes in the seasonal timing of ET from 19162003 are relatively small overall, and do not show great sensitivity to temperature-related effects. Greater temperature sensitivity is apparent during 1947-2003 in the warm parts of the domain (particularly CA). These effects, which are discussed in more detail in the following section, are due primarily to the combined effects of greater water inputs in spring (temperature effects on snowmelt timing), earlier emergence of snow-free conditions (which increases surface energy available for evaporation), and varying effects in summer associated with trends in precipitation. There are substantial trends in the simulations toward increased runoff earlier in the water year, and earlier SM recharge in spring. These trends are also most clearly related to temperature trends (compare the BR to FPR in Figs. 6 and 7). The warmest parts of the domain are most sensitive to warming in this regard, which is consistent with the trends in the timing of snowmelt shown by Hamlet et al. (2005). Because the temperature trends are larger dur- 

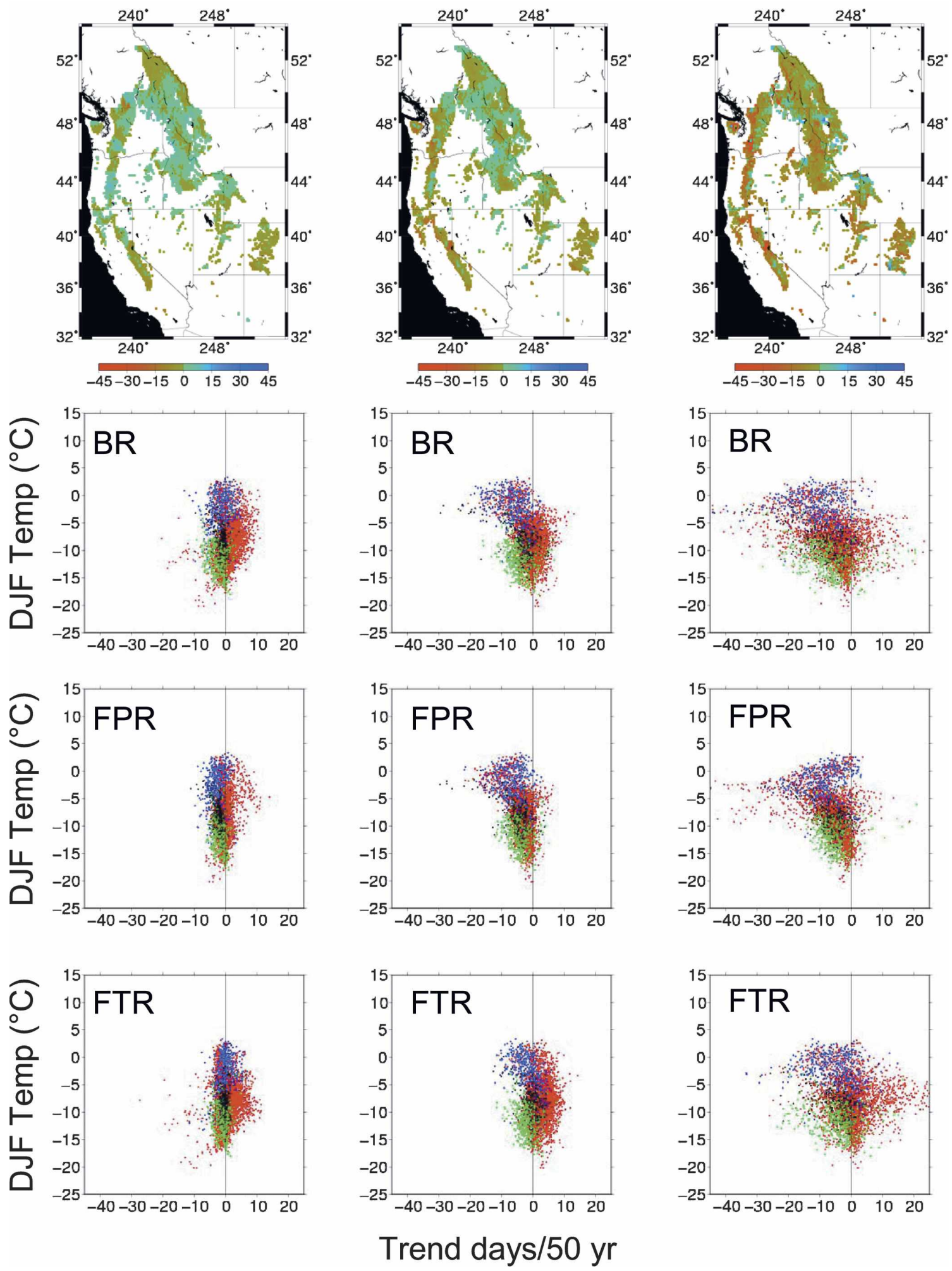

FIG. 6. 50-yr cumulative trends (annual trend times 50) in the timing of ET, runoff, and SM during 1919-2003 for cells with at least $50 \mathrm{~mm}$ of SWE on 1 April. (left) Trend in the date of $50 \%$ of total water year ET. (middle) Trend in the date of $50 \%$ of total water year runoff. (right) Trend in the date of $80 \%$ of peak water year SM. Spatial plots show the combined effects in the BR. Scatterplots show the cumulative trends as a function of DJF average temperature in each grid cell for the BR, FPR, and FTR, respectively. Scatterplots are color coded by region: red $=$ PNW, blue $=\mathrm{CA}$, green $=\mathrm{CRB}$, and black $=\mathrm{GB}$. 

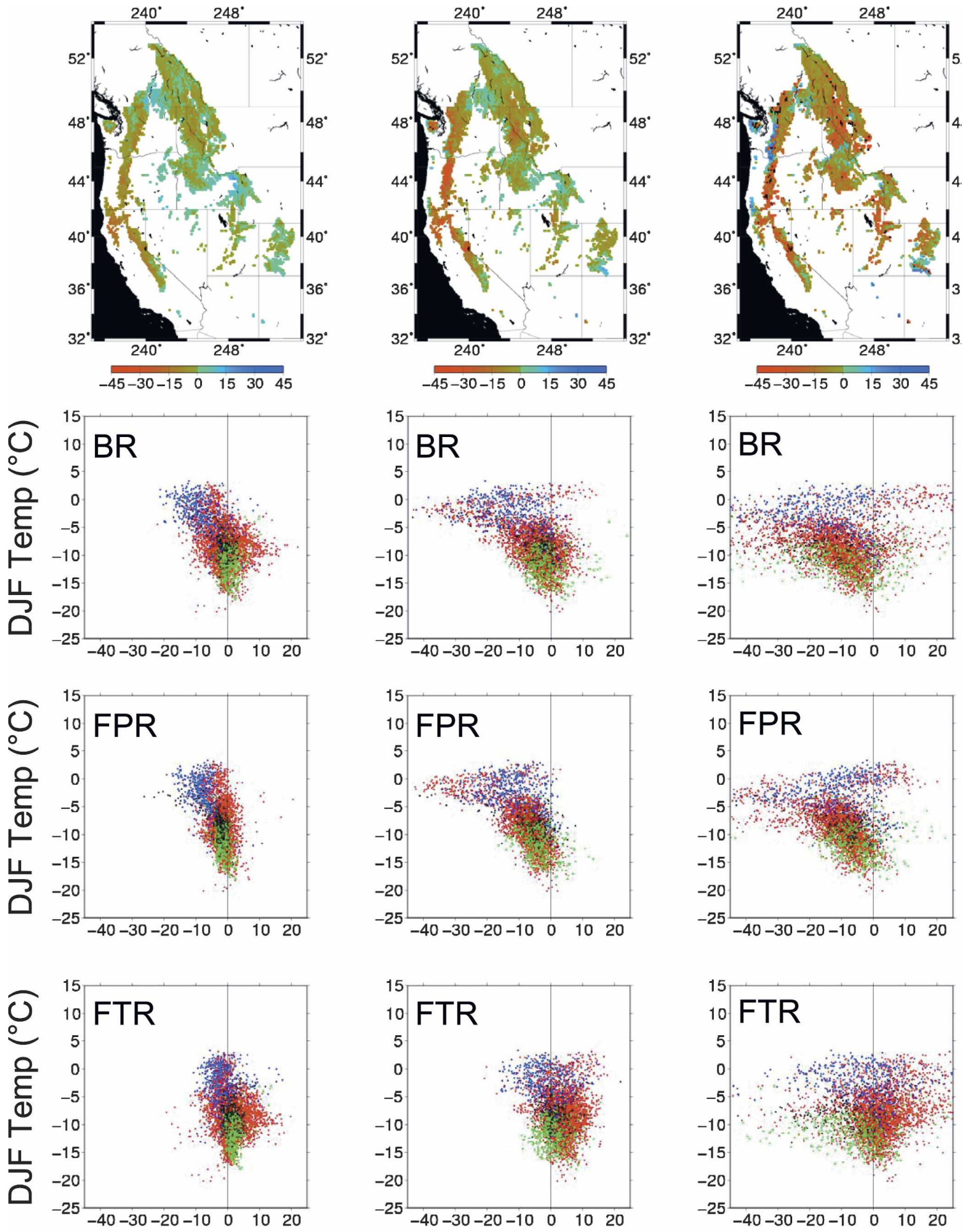

\section{Trend days $/ 50 \mathrm{yr}$}

FIg. 7. Same as in Fig. 6, but for the period during 1947-2003. 
ing 1947-2003 (Table 1), the temperature-related (and overall) trends in the timing of runoff and soil moisture recharge are much more pronounced for this time period (as are the changes in the timing of snow accumulation and melt). The effects on runoff and soil moisture recharge are discussed in more detail in subsequent sections.

\section{d. Trends in evapotranspiration and runoff ratio}

As noted in previous discussion, trends in ET in the simulations are primarily due to changes in inferred cloud cover (net surface radiation), changes in $T$ (saturated vapor pressure or inferred dewpoint), or changes in water availability at different times of the year, which can be influenced both by seasonal or annual changes in $P$ and/or snow dynamics. The snow-covered area (which is affected by both $T$ and $P$ ) may also play a role in determining ET in the spring because of effects on surface albedo. When examining all cells in the domain, the model simulations showed overall increasing trends in warm season ET (not shown) during both 1916-2003 and 1947-2003. However, additional analysis (not shown) showed that the overall trends in summer ET were most strongly associated with trends in $P$ in the current year. These results are broadly consistent with the fact that ET in the western United States is frequently water limited in the warm season (Fig. 5), and that there are in many cases increasing trends in summer $P$ in the model-driving data (Fig. 4; Table 1).

A somewhat different picture emerges, however, if we examine only those cells that have a least $50 \mathrm{~mm}$ of SWE on 1 April and examine the seasonality of the changes. Figure 8 shows the trends in ET during AprilJune and July-September for these grid cells. From April to June, water availability in these "snow cells" is much more strongly dependent on temperature trends, which cause earlier delivery of water (and higher SM) from the melting snowpack, and earlier emergence of snow-free ground in the simulations. These effects can be seen most clearly in Fig. 8 for 1947-2003 (Fig. 8, upper right panels). Trends associated with $P$ alone show no overall shift toward positive or negative trends, whereas the effects of $T$ trends alone result in strong increasing trends in ET, and clearly dominate the combined effects due to trends in both $T$ and $P$.

For July-September ET, the sensitivity to $T$ and $P$ is reversed. The $P$ effects dominate the combined results (compare scatterplots for BR to FTR in Fig. 8, lower panels) and the trends associated with $T$, while showing a relationship with winter temperature regimes, do not show a strong effect on overall trends (Fig. 9). In the most arid parts of the domain (e.g., in much of the GB and $\mathrm{CRB}$ ), we expect trends in late summer ET to be most clearly related to summer $P$ trends, because there is abundant energy available for evaporation and more $P$ simply results in more ET. In some other parts of the domain, however, the effects on ET are a more complex function of trends in cool season $P$ and $T$. In the warmer parts of the CA domain, for example, $P$ trends alone produce increasing trends in ET (more water availability due to greater cool season $P$ ), whereas the $T$ trends alone would decrease ET, because late summer water availability is decreased due to earlier snowmelt in this sensitive area. As it turns out, the $T$ trends dominate in this part of the domain, because CA has little summer $P$, and the strong effects of temperature on the timing of snowmelt dominate (Hamlet et al. 2005). This also explains the strong temperature-related shifts in the seasonal timing of ET shown for this part of the domain in Fig. 7. Trends in the annual runoff ratio $[($ annual runoff $) /($ annual $P)]$ are largely related to seasonal trends in $P$ (not shown). Figure 9 shows that trends in runoff ratio are most clearly related to trends in cool season $P$, and trends in warm season $P$ play a much smaller role. While considerable scatter is present in these relationships, in simple terms, increasing trends in cool season $P$ are frequently associated with increasing trends in the annual runoff ratio. The effects for 1916-2003 (not shown) are similar.

\section{e. Trends in runoff timing}

Trends in the seasonal timing of runoff in areas with substantial snow accumulation in the cool season are influenced by changes in snow and SM dynamics (Hamlet and Lettenmaier 1999; Stewart et al. 2005), although trends in the seasonality of $P$ may also play a role. Figure 10 shows trends in the fraction of annual runoff occurring in March and June, respectively, for all the cells with at least $50 \mathrm{~mm}$ of SWE on 1 April. The changes in runoff timing during 1947-2003 (right panels) are very similar to the observed trends in streamflow timing shown by Stewart et al. (2005) for essentially the same time period. Because the snow is melting systematically earlier in the model simulations (Hamlet et al. 2005), the simulated runoff fraction in March increases systematically, and the runoff fraction in June decreases systematically. For March the patterns are similar for 1916-2003 and 1947-2003, although the trends are stronger during 1947-2003. For June, the overall trends are generally downward during 19472003, but are not as consistent for the 1916-2003 period. Trends in runoff timing in June are also more strongly related to $P$ trends.

The overall trends in runoff timing in March and 

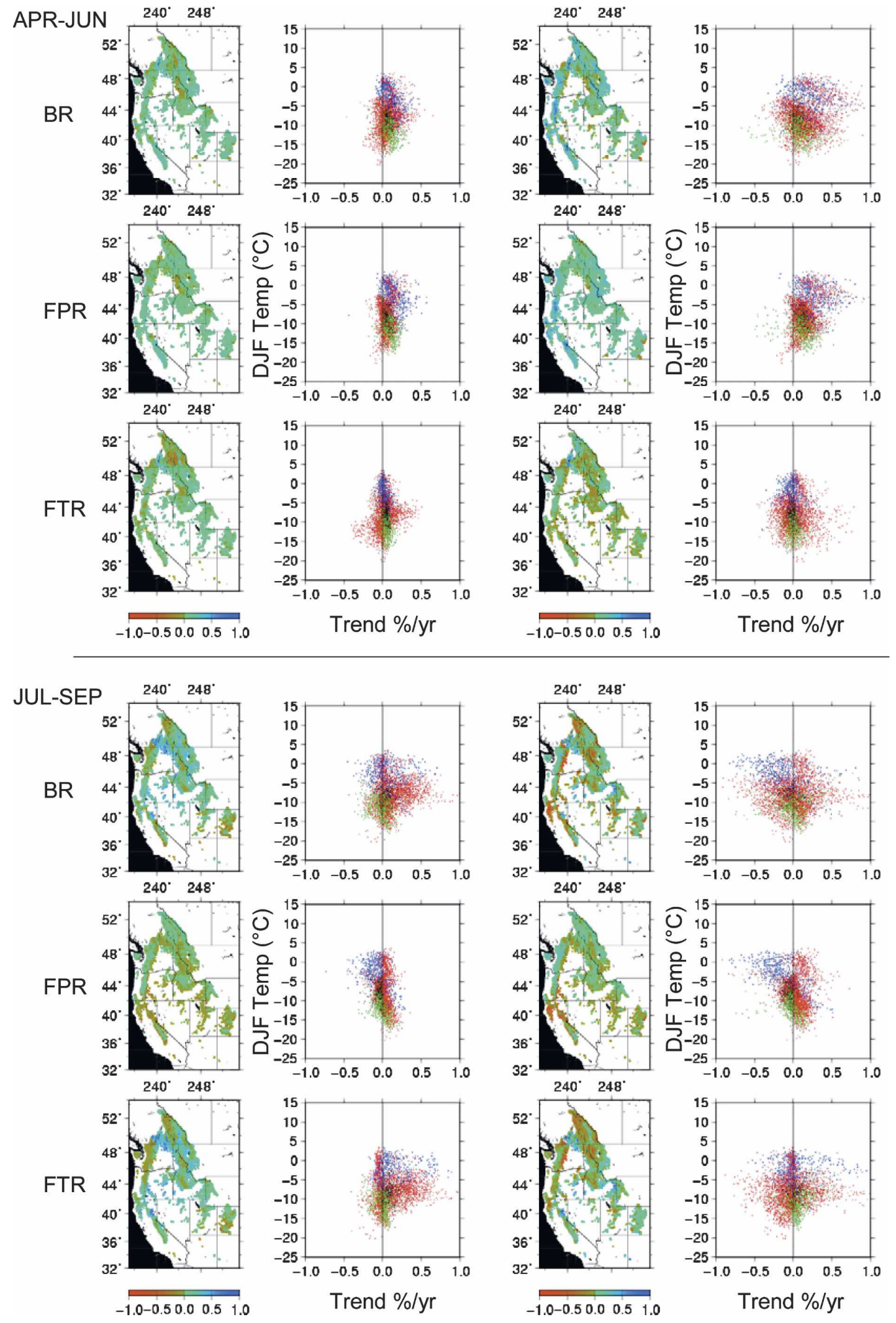

FIG. 8. Trends in (upper group of panels) April-June ET and T (lower group of panels) July-September E for VIC cells with more than $50 \mathrm{~mm}$ of average SWE on 1 April: trends during (left) 1916-2003 and (right) 1947-2003. The results for the (top) BR, (middle) FPR, and (bottom) FTR simulations. For each time period and model run a map of trends and a scatterplot of DJF temperature vs trend are shown. Scatterplots are color coded by region: red $=\mathrm{PNW}$, blue $=\mathrm{CA}$, green $=\mathrm{CRB}$, black $=\mathrm{GB}$. 

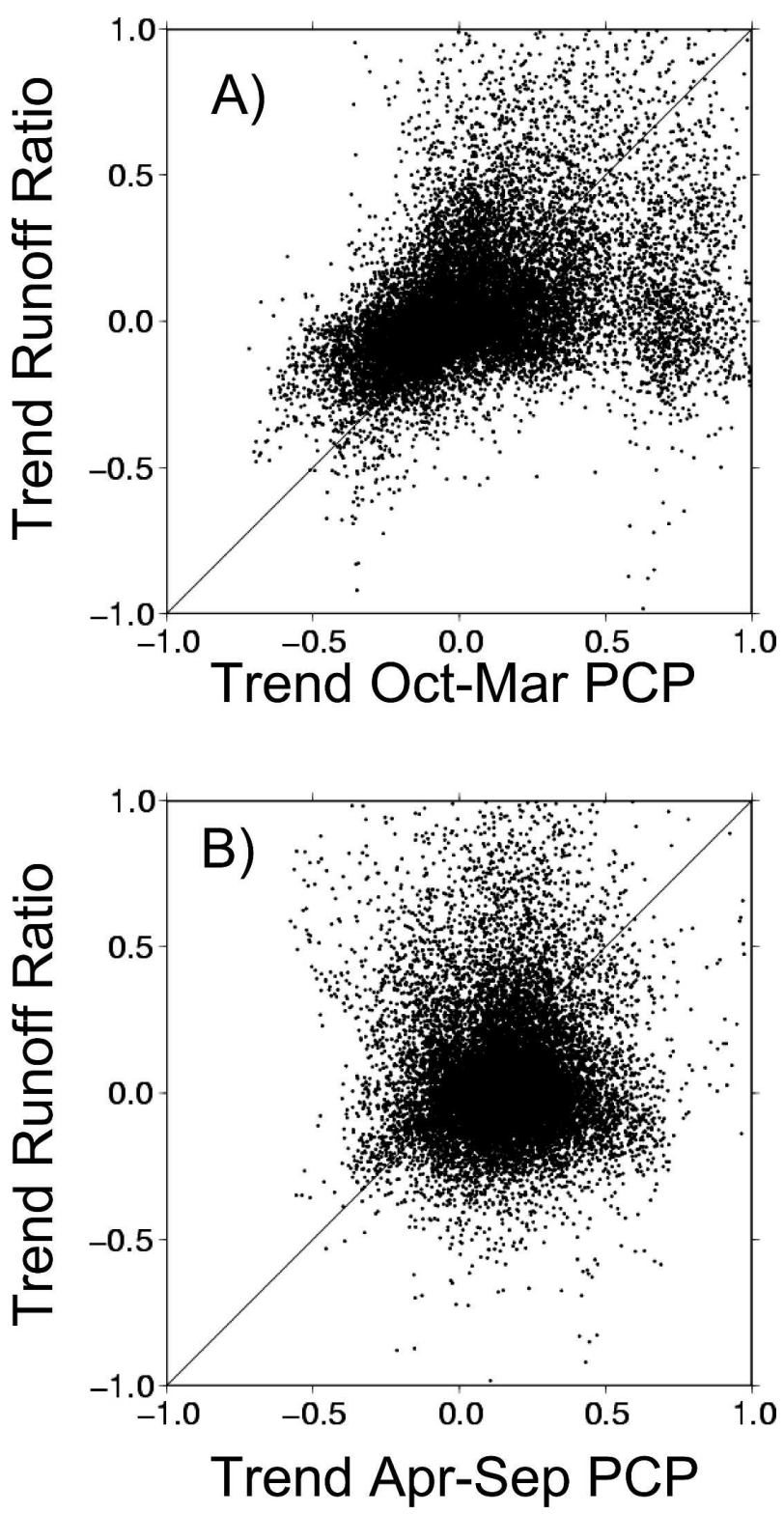

FIG. 9. Trends $\left(\% \mathrm{yr}^{-1}\right)$ in the annual runoff ratio from 1947 to 2003 compared to (a) trends in October-March $P\left(\% \mathrm{yr}^{-1}\right)$ for 1947-2003 and (b) trends in April-September $P\left(\% \mathrm{yr}^{-1}\right)$ over the same period.

June can be most clearly understood by first examining the effects of $T$ alone (middle rows of panels labeled FPR in Fig. 10). The trend in the fraction of runoff in March due to $T$ trends alone is typically upward, and is related to a combination of trends toward earlier snowmelt and earlier soil recharge (Figs. 6-7). Trends are greatest in the areas of the domain with midwinter temperatures between $-10^{\circ}$ and $-5^{\circ} \mathrm{C}$, since these areas experience peak snowmelt in the simulations during this month (Fig. 2). By June the trends in runoff frac- tion due to $T$ alone are predominantly negative across the board because by June, snowmelt in most of the domain has peaked and the shifts toward earlier snowmelt tend to reduce water availability in all but the very coldest parts of the domain. A similar analysis of each month and the four seasons (not shown) revealed a more gradual shift from increased runoff in the early spring to reduced runoff in the mid- to late summer. The monthly results also show that the shifts in runoff timing are related to winter temperature regimes, with shifts in timing starting earlier in the year in warmer parts of the domain and later in the colder parts of the domain. This is expected since the snowmelt peaks earlier in the warmer parts of the domain (Fig. 2). As a general rule, if the snowmelt is occurring earlier in time, then areas of the domain where the dates of peak snowpack occur after the month being examined will show upward trends in the fraction of runoff. Conversely, areas of the domain with peak snowpack occurring before the month being examined will show downward trends in runoff fraction for that month. Results for May, for example, (not shown) exhibit downward trends in the warmest areas of the domain (near-coastal areas in the PNW and CA) where peak snowmelt has already occurred, whereas in the coldest areas in the domain (e.g., in the PNW in British Columbia) trends in runoff fraction are still increasing in May because peak accumulation occurs later in these colder areas (Fig. 2).

As discussed in the introduction, many past studies of western U.S. river basins have shown that under a warmer climate, reduced runoff in late summer would occur due to earlier spring snowmelt. While downward trends due to warming are apparent in our simulations as well, the trends in the fraction of annual runoff occurring in late summer (not shown) are actually most clearly related to $P$ trends. This suggests that, the general sensitivity to warming not withstanding, trends in late summer low flows are not robustly linked to temperature trends alone.

\section{f. Trends in soil moisture}

Trends in SM are somewhat more difficult to analyze than trends in runoff or ET, because SM integrates the time history of inputs from $P$ (rain), snowmelt, and losses due to ET, surface runoff, and drainage (base flow). The SM is also characterized by strong autocorrelation in time, which means that lagged effects in inputs or losses can be as important as those occurring at the time the impacts are actually observed. In snowmelt-dominant watersheds in particular, interannual SM variations observed in midsummer are most clearly associated with variability in snow accumulation that is 

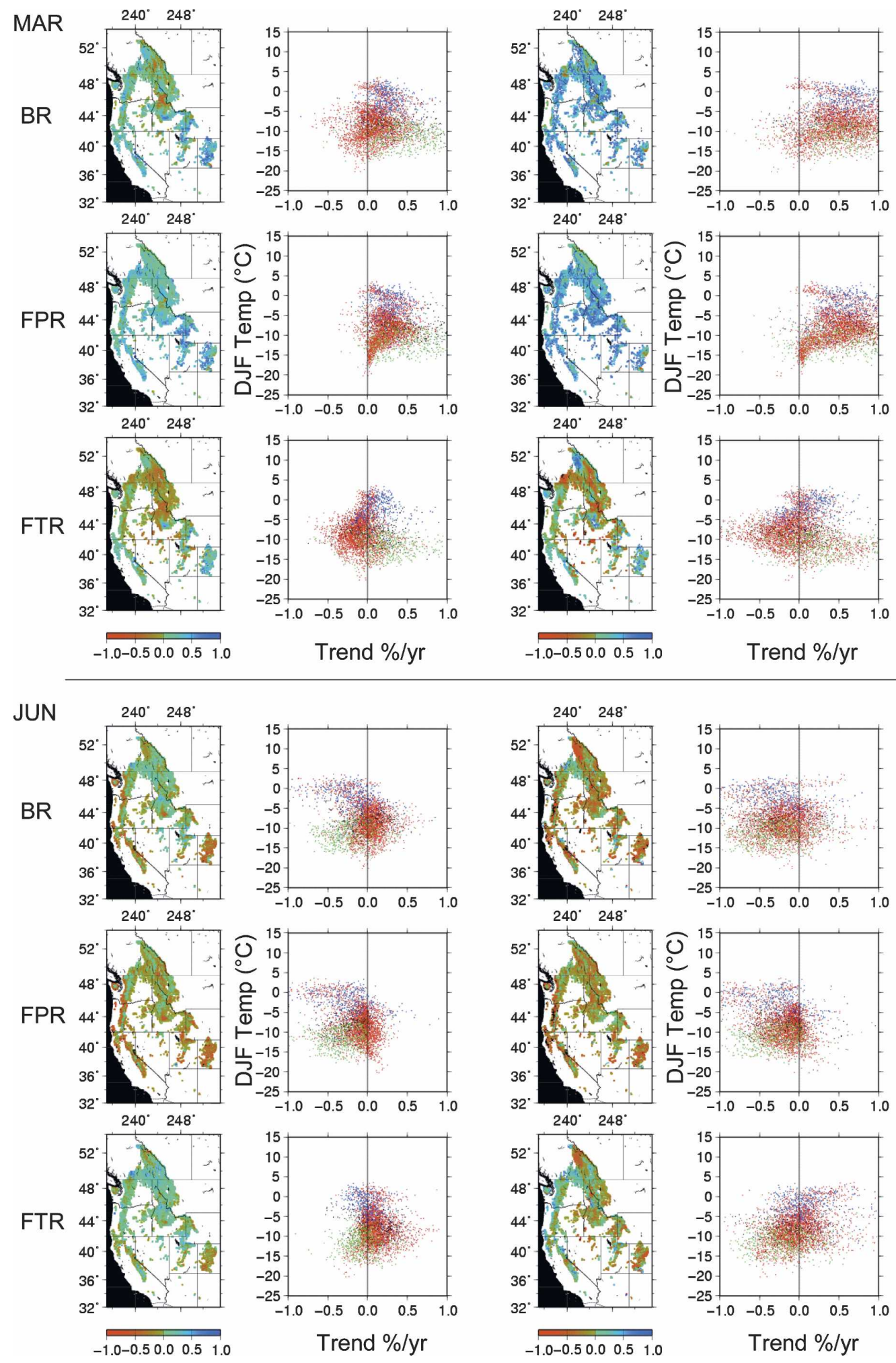

FIG. 10. Trends in the fraction of water year runoff occurring in (upper group of panels) March and (lower group of panels) June for VIC cells with more than $50 \mathrm{~mm}$ of average snow water equivalent on 1 April. (left of center) Trends from 1916 to 2003 and (right of center) trends for 1947-2003. (top row of each grouping) The results for the BR simulations, (middle row of each grouping) the results for the FPR, and (bottom row of each grouping) results for the FTR. For each month, time period, and model run a map of trends $\left(\% \mathrm{yr}^{-1}\right)$ and a scatterplot of DJF temperature ( $y$ axis) vs trend ( $x$ axis) are shown. Scatterplots are also color coded by region: red $=\mathrm{PNW}$, blue $=\mathrm{CA}$, green $=\mathrm{CRB}$, black $=\mathrm{GB}$. 
largely determined by climatic conditions occurring as much as 8 months earlier (Fig. 5).

Trends in SM are reported here as relative trends (absolute trend divided by the long-term mean value) of first of month SM values. We show figures for 1 April and 1 July because changes in SM on these dates roughly correspond to changes in runoff for March and June (Fig. 10). If increasing trends in snowmelt and/or $P$ falling as rain are apparent in March, for example, then we should see increasing trends in SM on 1 April.

On 1 April, increasing trends in SM predominate and are shown to be about equally related to $T$ and $P$ effects. The results are more strongly temperature related for 1947-2003, during which strong temperaturerelated effects weaken or reverse the effects of downward trends in $P$ in the PNW (Fig. 11). For 1 July 1 [(lower group of panels in Fig. 11)] the effects of $P$ dominate the overall trends, except in the warmest parts of the domain. The temperature-related trends are generally consistent with the changes in runoff discussed above [i.e., warm areas show stronger downward trends on 1 July than cold areas (as for June runoff trends in Fig. 10)] and the $T$-related trends are stronger during 1947-2003 than 1916-2003.

Despite the fact that the $T$-related trends play a smaller role in determining overall trends in 1 July SM, the effects due to temperature are clearly reflected in the BR results, and systematically shift the trends associated with $P$ alone one way or the other (Fig. 11). In some specific cases, the effects of $T$ are the predominant driver of SM trends in midsummer. On 1 July, for example, the FTR trends for the cells with warm winter temperatures are small, whereas the trends for the FPR are larger and essentially determine the BR trends for cells within this climatic regime. This makes sense, because these parts of the domain get relatively little $P$ in summer (Fig. 5), and are subject to strong timing shifts in snowmelt timing, which are primarily $T$ related (Hamlet et al. 2005).

\section{Summary and conclusions}

Increasing trends in $T$ are apparent in the gridded meteorological datasets used in this study for both periods: 1916-2003 and 1947-2003. Daily minimum temperatures are rising faster than maximum temperatures, and the $T$ trends are much larger during 1947-2003. These trends are, by construct, consistent with observed trends in the quality controlled HCN and HCCD datasets.

The $P$ trends have been positive over much of the western United States during 1916-2003, but there have been large decadal excursions from these long-term trends, and upward trends during 1916-2003 are most clearly associated with widespread drought in the early part of the record. In contrast to the effects of $T$ trends, which are quite spatially homogeneous, $P$ trends show little evidence of spatially consistent long-term trends in the western United States. Hydrologic trends related to $P$ during 1916-2003 (increasing trends in $P$ ) are inconsistent with those during 1947-2003 (decreasing trends in $P$ ) in the PNW, for example.

Trends in simulated warm season ET as a whole have followed trends in $P$; however, in cells with substantial snow accumulation in spring, some systematic changes associated with temperature are also apparent. In early spring, water availability from snowmelt has generally increased due to earlier snowmelt, and ET during April-June has followed these upward trends. Earlier snowmelt may also increase ET due to effects on albedo related to the earlier emergence of snow-free ground in the simulations. In late summer, increasing $T$ in the simulations results in decreasing trends in water availability from snowmelt, which has tended to reduce ET during July-September. These changes result in changes in the date of $50 \%$ of water year ET, particularly for the warmer areas of the domain during 19472003.

Increasing temperatures have had an important effect on the seasonal nature of runoff in cells with substantial snow accumulation in spring. In March, trends in the fraction of water year runoff are strongly upward and are predominantly associated with temperature effects. In June, temperature-related trends are strongly downward. Temperature plays a strong role in determining the overall trends in both months but is more important in March. These changes result in robust shifts in the timing of runoff toward earlier calendar dates that are primarily controlled by temperature trends. By September, however, the $T$ related trends are relatively weak, and $P$ trends begin to dominate the overall trends. These results suggest that trends in low flows in late summer are mostly controlled by $\mathrm{P}$ trends.

Trends in the 1 April SM in cells with significant snow accumulation on spring are upward (i.e., earlier soil recharge) and are most strongly controlled by $T$ related trends. On 1 July, the $T$-related effects are weaker and precipitation is the major driver of the overall trends in most parts of the domain. Areas with little $P$ in summer and large trends in snowmelt timing (e.g., coastal areas of the PNW and CA), however, show strong effects associated with temperature alone. Consistent with these effects, trends in the timing of soil moisture recharge in spring are toward earlier dates, and, same as for the trends in fraction of runoff occur- 

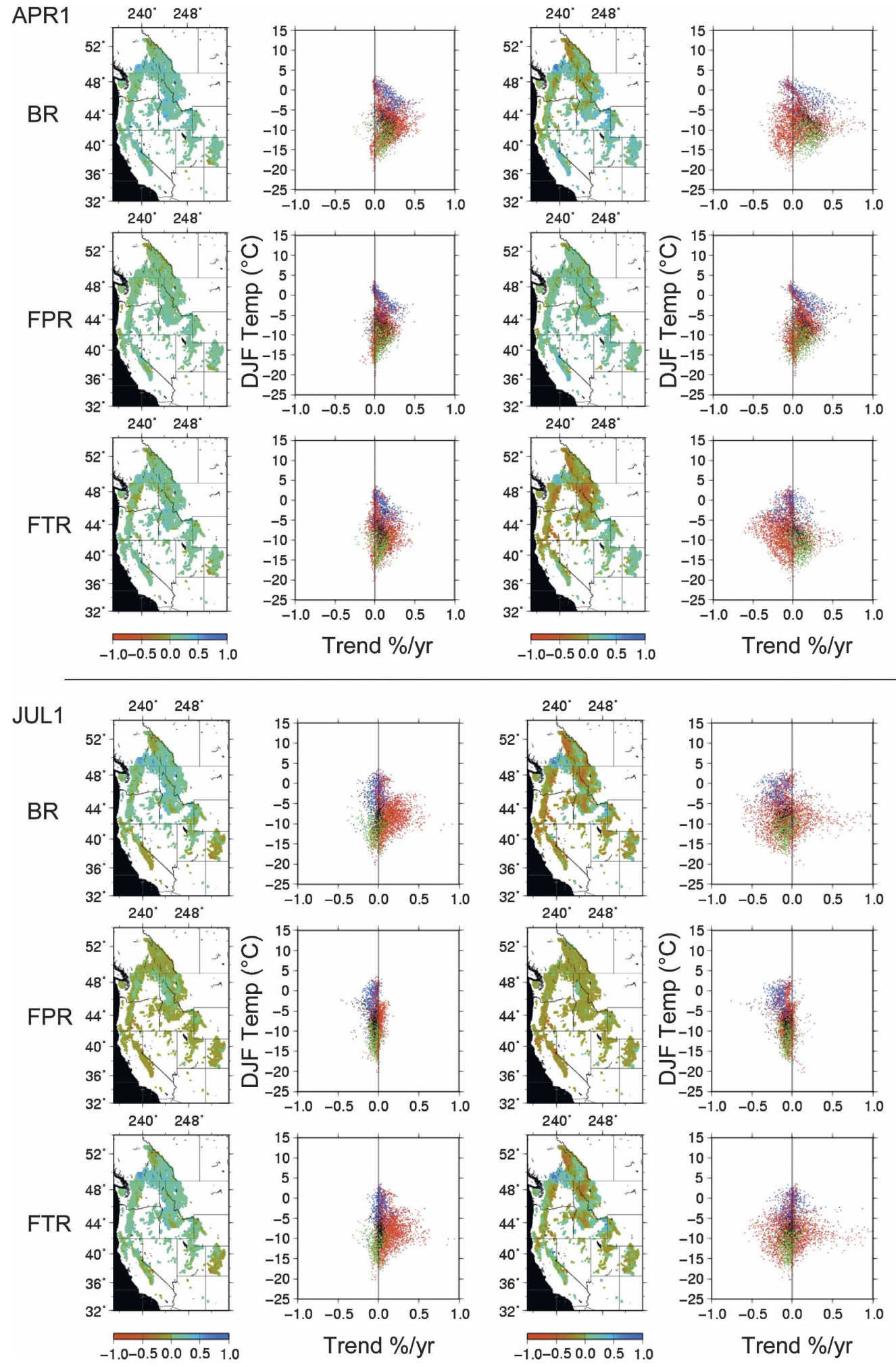

FIG. 11. Trends in (upper group of panels) 1 April soil moisture and (lower group of panels) 1 July soil moisture for VIC cells with more than $50 \mathrm{~mm}$ of average snow water equivalent on 1 April. (left of center) Trends from 1920 to 2003 and (right of center) trends for 1947-2003. (top row of each grouping) The results for the BR simulations, (middle row of each grouping) the results for the FPR, and (bottom row of each grouping) the results for the FTR. For each month, time period, and model run a map of trends $\left(\% \mathrm{yr}^{-1}\right)$ and a scatterplot of DJF temperature ( $y$ axis) vs trend $(x$ axis) are shown. Scatterplots are also color coded by region: red $=$ PNW, blue $=\mathrm{CA}$, green $=\mathrm{CRB}$, black $=\mathrm{GB}$. 
ring in the 1 March and 1 April SM, are primarily controlled by temperature trends.

Many studies evaluating global warming projections have concluded that much greater confidence should be placed in projections of increasing $T$ than in changes in $P$ (Houghton et al. 2001). The results of this study are useful in this context, because we have been able to show how strongly ET, runoff, and SM are affected by $T$ and $P$ trends. We can conclude, for example, that future projections of changes in runoff in spring and summer are likely to be more reliable in general than projections of changes in late summer SM. Furthermore, changes in the seasonal timing of ET in summer in coastal areas of the PNW and CA are much more clearly related to temperature changes, because there is relatively little $\mathrm{P}$ in summer to offset losses of water availability due to earlier snowmelt.

Likewise, in global warming studies the use of a discrete sensitivity analysis to separately analyze the effects of $T$ and $P$ changes may have value in terms of analyzing the uncertainties inherent in such projections. For example, forecasts of different hydrologic conditions associated with $T$ and $P$ changes could be weighted differently in the final analysis based on estimates of the reliability of simulated $T$ and $P$ trends as compared to observations.

Acknowledgments. This publication was funded by the Joint Institute for the Study of the Atmosphere and Ocean (JISAO) at the University of Washington under NOAA Cooperative Agreement NA17RJ1232.

\section{REFERENCES}

Cherkauer, K. A., and D. P. Lettenmaier, 2003: Simulation of spatial variability in snow and frozen soil. J. Geophys. Res., 108, 8858, doi:10.1029/2003JD003575.

Christensen, N. S., A. W. Wood, N. Voisin, D. P. Lettenmaier, and R. N. Palmer, 2004: Effects of climate change on the hydrology and water resources of the Colorado River Basin. Climatic Change, 62, 337-363.

Cleveland, W. S., 1993: Visualizing Data. Hobart Press, 360 pp.

Cosgrove, B. A., and Coauthors, 2003: Land surface model spinup behavior in the North American Land Data Assimilation System (NLDAS). J. Geophys. Res., 108, 8845, doi:10.1029/ 2002JD003316.

Daly, C., R. Neilson, and D. Phillips, 1994: A statistical-topographic model for mapping climatological precipitation over mountainous terrain. J. Appl. Meteor., 33, 140-158.

Gleick, P. H., 2000: Water: The Potential Consequences of Climate Variability and Change for the Water Resources of the United States. Pacific Institute for Studies in Development, Environment, and Security, $151 \mathrm{pp}$.

Hamlet, A. F., and D. P. Lettenmaier, 1999: Effects of climate change on hydrology and water resources in the Columbia River Basin. J. Amer. Water Res. Assoc., 35, 1597-1623.

$\ldots$, and — 2005: Production of temporally consistent gridded precipitation and temperature fields for the continental United States. J. Hydrometeor., 6, 330-336.

_, P. W. Mote, M. P. Clark, and D. P. Lettenmaier, 2005: Effects of temperature and precipitation variability on snowpack trends in the western United States. J. Climate, 18, 4545-4561.

Houghton, J. T., Y. Ding, D. J. Griggs, M. Noguer, P. J. van der Linden, X. Dai, K. Maskell, and C. A. Johnson, Eds., 2001: Climate Change 2001: The Scientific Basis. Cambridge University Press, $881 \mathrm{pp}$.

Karl, T. R., C. N. Williams Jr., F. T. Quinlan, and T. A. Boden, 1990: United States Historical Climatology Network (HCN) serial temperature and precipitation data. Environmental Science Division, Publication 3404, Carbon Dioxide Information and Analysis Center, Oak Ridge National Laboratory, Oak Ridge, TN, 389 pp.

Knowles, N., and D. R. Cayan, 2002: Potential effects of global warming on the Sacramento/San Joaquin watershed and the San Francisco estuary. Geophys. Res. Lett., 29, 1891, doi:10.1029/2001GL014339.

— logic changes in the San Francisco Estuary and watershed. Climatic Change, 62, 319-336.

- M. D. Dettinger, and D. R. Cayan, 2006: Trends in snowfall versus rainfall in the western United States. J. Climate, 19, $4545-4559$.

Lettenmaier, D. P., A. W. Wood, R. N. Palmer, E. F. Wood, and E. Z. Stakhiv, 1999: Water resources implications of global warming: A US regional perspective. Climatic Change, 43, 537-579.

Liang, X., D. P. Lettenmaier, E. F. Wood, and S. J. Burges, 1994: A simple hydrologically based model of land surface water and energy fluxes for general circulation models. J. Geophys. Res., 99 (D7), 14 415-14 428.

Mantua, N., S. Hare, Y. Zhang, J. M. Wallace, and R. Francis, 1997: A Pacific interdecadal climate oscillation with impacts on salmon production. Bull. Amer. Meteor. Soc., 78, 10691079.

Maurer, E. P., A. W. Wood, J. C. Adam, D. P. Lettenmaier, and B. Nijssen, 2002: A long-term hydrologically based dataset of land surface fluxes and states for the conterminous United States. J. Climate, 15, 3237-3251.

Mekis, É., and W. D. Hogg, 1999: Rehabilitation and analysis of Canadian daily precipitation time series. Atmos.-Ocean, 37, 53-85.

Miller, N. L., K. E. Bashford, and E. Strem, 2003: Potential impacts of climate change on California hydrology. J. Amer. Water Res. Assoc., 39, 771-784.

Mote, P. W., 2006: Climate-driven variability and trends in mountain snowpack in western North America. J. Climate, 19, 6209-6220.

— , and Coauthors, 2003: Preparing for climatic change: The water, salmon, and forests of the Pacific Northwest. Climatic Change, 61, 45-88.

- A. F. Hamlet, M. P. Clark, and D. P. Lettenmaier, 2005: Declining mountain snowpack in western North America. Bull. Amer. Meteor. Soc., 86, 39-49.

Nijssen, B., R. Schnur, and D. P. Lettenmaier, 2001: Global retrospective estimation of soil moisture using the variable infiltration capacity land surface model, 1980-93. J. Climate, 14, 1790-1808.

Payne, J. T., A. W. Wood, A. F. Hamlet, R. N. Palmer, and D. P. Lettenmaier, 2004: Mitigating the effects of climate change 
on the water resources of the Columbia River basin. Climatic Change, 62, 233-256.

Regonda, S., B. Rajagopalan, M. Clark, and J. Pitlick, 2005: Seasonal cycle shifts in hydroclimatology over the western United States. J. Climate, 18, 372-384.

Robock, A., and Coauthors, 2003: Evaluation of the North American Land Data Assimilation System over the Southern Great Plains during the warm season. J. Geophys. Res., 108, 8846, doi:10.1029/2002JD003245.

Serreze, M. C., M. P. Clark, R. L. Armstrong, D. A. McGinnis, and R. S. Pulwarty, 1999: Characteristics of the western United States snowpack from snowpack telemetry (SNOTEL) data. Water Resour. Res., 35, 2145-2160.

Service, R. F., 2004: As the west goes dry. Nature, 303, 1124-1127.

Shuttleworth, W. J., 2003: Evaporation. Handbook of Hydrology, D. R. Maidment, Ed., McGraw-Hill, 4.1-4.53.

Stewart, I. T., D. R. Cayan, and M. D. Dettinger, 2004: Changes in snowmelt runoff timing in western North America under a "business as usual" climate change scenario. Climatic Change, 62, 217-232.

,$- \ldots$, and $\longrightarrow$, 2005: Changes toward earlier streamflow timing across western North America. J. Climate, 18, 11361155.

Thornton, P. E., and S. W. Running, 1999: An improved algorithm for estimating incident daily solar radiation from measurements of temperature, humidity, and precipitation. Agric. For. Meteor., 93 (4), 211-228.

Van Rheenen, N. T., A. W. Wood, R. N. Palmer, and D. P. Lettenmaier, 2004: Potential implications of PCM climate change scenarios for Sacramento-San Joaquin River Basin hydrology and water resources. Climatic Change, 62, 257-281.

Vincent, L. A., and D. W. Gullett, 1999: Canadian historical and homogeneous temperature datasets for climate change analyses. Int. J. Climatol., 19, 1375-1388. 